\title{
Review of Science Issues, Deployment Strategy, and Status for the ARM North Slope of Alaska-Adjacent Arctic Ocean Climate Research Site
}

\author{
K. StAmnes \\ Geophysical Institute, University of Alaska, Fairbanks, Fairbanks, Alaska \\ R. G. ELLingSON \\ Department of Meteorology, University of Maryland, College Park, Maryland \\ J. A. CURRY \\ Department of Aerospace and Engineering Sciences, University of Colorado, Boulder, Colorado \\ J. E. WALSH \\ Department of Atmospheric Sciences, University of Illinois, Urbana-Champaign, Urbana, Illinois \\ B. D. ZAK \\ Sandia National Laboratories, Albuquerque, New Mexico
}

(Manuscript received 1 November 1994, in final form 9 January 1998)

\begin{abstract}
Recent climate modeling results point to the Arctic as a region that is particularly sensitive to global climate change. The Arctic warming predicted by the models to result from the expected doubling of atmospheric carbon dioxide is two to three times the predicted mean global warming, and considerably greater than the warming predicted for the Antarctic. The North Slope of Alaska-Adjacent Arctic Ocean (NSA-AAO) Cloud and Radiation Testbed (CART) site of the Atmospheric Radiation Measurement (ARM) Program is designed to collect data on temperature-ice-albedo and water vapor-cloud-radiation feedbacks, which are believed to be important to the predicted enhanced warming in the Arctic. The most important scientific issues of Arctic, as well as global, significance to be addressed at the NSA-AAO CART site are discussed, and a brief overview of the current approach toward, and status of, site development is provided. ARM radiometric and remote sensing instrumentation is already deployed and taking data in the perennial Arctic ice pack as part of the SHEBA (Surface Heat Budget of the Arctic Ocean) experiment. In parallel with ARM's participation in SHEBA, the NSA-AAO facility near Barrow was formally dedicated on 1 July 1997 and began routine data collection early in 1998. This schedule permits the U.S. Department of Energy's ARM Program, NASA's Arctic Cloud program, and the SHEBA program (funded primarily by the National Science Foundation and the Office of Naval Research) to be mutually supportive. In addition, location of the NSA-AAO Barrow facility on National Oceanic and Atmospheric Administration land immediately adjacent to its Climate Monitoring and Diagnostic Laboratory Barrow Observatory includes NOAA in this major interagency Arctic collaboration.
\end{abstract}

\section{Introduction and background}

In this paper, we discuss the high-latitude Cloud and Radiation Testbed (CART) site now being established on the North Slope of Alaska as part of the Atmospheric Radiation Measurement (ARM; Stokes and Schwartz 1994) program. We provide an overview of the scientific

Corresponding author address: Dr. Knut Stamnes, Geophysical Institute, University of Alaska, Fairbanks, 903 Koyukuk Drive, P.O. Box 757320, Fairbanks, AK 99775-0800. issues to be addressed at the North Slope of AlaskaAdjacent Ocean (NSA-AAO) CART site and discuss how these and complementary issues are being addressed by ARM and other national and international programs.

At present, general circulation models (GCMs) constitute the primary tool available for assessing our understanding of the global climate system, including climate sensitivity to the increasing greenhouse gas concentrations in the atmosphere. These models indicate that the Arctic is particularly sensitive to a doubling of carbon dioxide. Thus, although there are significant dif- 
ferences between individual models, and between models and observations, GCMs tend to predict a strong warming in the Arctic that is two to three times the mean global warming, and considerably greater than the projected Antarctic warming (IPCC 1992).

A recent assessment of GCM simulations of Arctic air temperatures by 19 different GCMs (Tao et al. 1996), indicates that 1 ) there is a $1^{\circ}-3^{\circ} \mathrm{C}$ cold bias in the models (compared with observations) over the continents (strongest over Eurasia) during spring, which is consistent with the absence of vegetative masking of the high-albedo snow; 2) there is a warm bias of $3^{\circ} \mathrm{C}$ over the Arctic Ocean during spring, which is comparable to that resulting from a carbon dioxide doubling in climate model experiments; 3) models with higher prescribed albedo values tend to have lower temperatures; and 4) models with higher cloudiness yield lower temperatures than the others during summer and autumn, but do not yield higher temperatures in winter.

As noted by Tao et al. (1996), the model assessment suffers from several limitations arising from both models and observations: 1) different specifications of sea ice (albedo, thickness) among the models; 2) no physically based links between cloudiness and air temperature, because only "total cloud fractions" are used; 3) differences in model resolution and in formulation of various physical processes; and 4) uncertainties in the observational database, which limit the ability to assess model performance. In spite of these caveats, the results of the model intercomparisons suggest that the highest priorities for improved simulation of Arctic temperatures are the proper treatment of 1) cloud-radiative interactions and 2) local surface-atmosphere interactions (Tao et al. 1996).

\section{a. Rationale for a high-latitude ARM site}

At high latitudes, it is sufficiently cold that ice is the predominant form of water much of the year, both in the air (ice clouds, diamond dust, and snow) and on the surface. Ice and snow scatter, transmit, and absorb solar and thermal infrared radiation differently from liquid water. In addition, the annual average radiative energy input is negative at high latitudes; that is, more energy is radiated to space than is received from the sun. The difference is made up by energy transported from lower latitudes by the atmosphere and the oceans. Thus, high latitudes serve as the "heat sink" for the global climate engine (Nakamura and Oort 1988).

Furthermore, because it is so cold, there is little water vapor in the atmosphere during much of the year, and that fact significantly changes the nature of infrared radiative energy flows. At $70^{\circ} \mathrm{N}$, the zonal and monthly mean column-integrated precipitable water ranges from $2.9 \mathrm{~mm}$ in February and March to $16.2 \mathrm{~mm}$ in July (Serreze et al. 1995a). Over the Arctic Ocean, the average precipitable water for $80^{\circ}-90^{\circ} \mathrm{N}$ is $1.8 \mathrm{~mm}$ in winter, and reaches a maximum of $12.5 \mathrm{~mm}$ in July (Serreze et al. 1995b). Because of this extreme dryness, the water vapor rotation band in the $300-600 \mathrm{~cm}^{-1}$ (about 16-33 $\mu \mathrm{m}$ wavelength) region plays an important role in surface and near-surface radiative cooling at high latitudes. By comparison, at mid and low latitudes this window is essentially closed at the surface. The lower temperatures at high latitudes also shift more of the radiant energy distribution (Planck function) into this spectral region. It is important to note, however, that since the upper troposphere is cold and dry globally, and the loss of radiative energy to space takes place in this region of the atmosphere, studies at the NSA-AAO site have the potential to contribute not only to a better understanding of Arctic climate, but also of climate issues that are global in scope.

During that part of the year when sunlight is scarce or absent, very strong, persistent surface temperature inversions form (Sverdrup 1933; Belmont 1957; Orvig 1970; Vowinckel and Orvig 1970; Maykut and Church 1973; Holmgren et al. 1975; Kahl 1990; Bradley et al. 1992; Kahl et al. 1992; Serreze et al. 1992) and influence atmospheric processes, especially cloud formation, evolution, and dissipation. Topics related to atmospheric temperature and humidity structure, and cloud formation and evolution processes, in the Arctic are reviewed elsewhere (Curry et al. 1996) and will therefore not be discussed here. Suffice it to note that, except in midsummer, ice and mixed-phase (liquid and water) clouds are present in the Arctic boundary layer, and are relatively easily investigated from the ground. Ice clouds, in the form of cirrus, are present on a global scale, but much higher in the atmosphere, and therefore not so easily accessible to in situ probing. The NSA-AAO site may be viewed as a natural ice cloud laboratory that will allow us to study processes determining the radiative impact of cirrus clouds, which are believed to play a very important role in the climate system.

\section{b. Influences of high latitudes on global climate}

The transport of water and sea ice from the Arctic Ocean into the deep-water formation zone of the North Atlantic affects the global ocean thermohaline circulation (Broecker et al. 1988; Delworth et al. 1993), and cloud-radiation feedbacks influence the mass balance and stability of the Arctic ice pack (e.g., Curry et al. 1993). Results from coupled ocean-atmosphere GCMs suggest that the global ocean circulation, which depends upon high-latitude radiative and other processes, can be seriously affected by the ongoing changes in atmospheric composition (Manabe et al. 1991). Ocean currents are known to have profound climatic influence, and changes in the strength and distribution of ocean currents provide for global propagation of the influences of high-latitude climate change. Although the ocean currents themselves are not within the charter of ARM, the changes in cloud-radiation-sea ice-ocean interactions definitely are, and these changes may, in turn, affect the 
global ocean circulation (Koerner 1973; Barry et al. 1993).

Snow-ice albedo feedback influences regional and even global radiant energy flows (e.g., Budyko 1969; Spelman and Manabe 1984; Dickinson et al. 1987; Ingram et al. 1989). Snow and ice have high reflectance (albedo) in the visible portion of the electromagnetic spectrum, where most of the solar radiation transmitted to the earth's surface resides (e.g., Wiscombe 1975; Warren and Wiscombe 1980; Wiscombe and Warren 1980; Warren 1982; Shine 1984). When the snow and/or ice melts, the albedo falls precipitously, resulting in the absorption of much more of the incident energy from the sun at the surface, and the reflection of a smaller fraction back to the atmosphere. The decrease in albedo tends to further heat the surface, accelerate the melting, and thus lead to the absorption of yet more energy, thereby giving positive feedback.

The secondary aspects of this feedback, which influence its net effect, are poorly understood. For instance, melting may result in increased cloud formation, which may change the snow-ice albedo feedback, since clouds have high albedo as well. However, clouds also trap thermal infrared radiation, leading to a warming. The net effect of changes in cloudiness (warming or cooling) depends on cloud microphysical properties such as cloud phase (ice and/or liquid water); ice-droplet particle size; vertical distribution; and macrophysical properties, such as cloud morphology (cloud shape and broken cloudiness), cloud location (base altitude and physical thickness), and cloud liquid-ice water spatial distribution (horizontal as well as vertical inhomogeneity). The present state of knowledge does not permit us to ascertain even the sign of the cloud feedback (warming or cooling). It is generally believed that low clouds (boundary layer stratus) lead to cooling (the albedo effect dominates over the infrared cloud greenhouse effect) whereas the opposite situation seems to prevail for high clouds (cirrus).

In the Arctic, the cloud-radiation feedback is further complicated by the presence of high-albedo snow-ice surfaces, and the scarcity of sunshine through the long winter. This leads to reversal of the feedback for low clouds (warming rather than cooling) except for about one month, around summer solstice, when the sun is higher and the albedo is lower than during the rest of the year [see Curry et al. (1996) for a discussion of a variety of feedback mechanism operative in the Arctic]. It is important to keep in mind, however, that the icealbedo and the cloud-radiation feedbacks seem to be inextricably linked to one another (as well as to other feedback mechanisms involving temperature, water vapor, etc.); studying one in isolation from the others may be quite misleading.

About $33 \%$ of the global carbon is presently immobilized in the active layer and permafrost underlying about $20 \%-25 \%$ of the earth's land surface. In fact, a recent study notes that the carbon stored in the upper permafrost and active layer of northern ecosystems is equivalent to $60 \%$ of the $750 \mathrm{Gt}$ of carbon now in the atmosphere (Weller et al. 1995). The permafrost temperature has increased about $2^{\circ}-4^{\circ} \mathrm{C}$ during the last $40-$ $80 \mathrm{yr}$ on the North Slope of Alaska (Lachenbruch and Marshall 1986), while the mean air temperature during the same period was about $-12.1 \pm 1.1^{\circ} \mathrm{C}$ (Zhang and Osterkamp 1993). Changes in seasonal snow cover may account for the permafrost surface warming (Zhang and Osterkamp 1993). Recent measurements (1983-93) indicate that the permafrost surface temperature cycled consistently with the 10-11 yr sunspot cycle (Osterkamp et al. 1994). A multidecade record of active layer variations at Barrow, Alaska, shows that warm-dry and warm-moist summers produced deep thaws in some years and shallow thaws in others (Brown et al. 1994). Summer air temperature, rainfall, and soil moisture data do not adequately explain the thaw variations, and it appears that interannual differences in surface energy regimes and canopy-soil properties play important roles in modifying the active layer thickness (Brown et al. 1994). Potential thawing of the permafrost is hypothesized to cause the release of carbon in the form of greenhouse gases (methane and carbon dioxide) from the tundra, making the Arctic a net source rather than a sink of atmospheric carbon (Cappellaz et al. 1993; Oechel et al. 1993), at least in warm and dry conditions. This phenomenon represents potential positive feedback.

Interpretation of satellite remote sensing data, to quantify the distribution and character of high-latitude clouds, snow and sea ice, is an important, but poorly solved problem. Satellite data have proven to be invaluable for both global climate monitoring and climate process studies, but the quality of current analysis of satellite datasets for the polar regions under cloudy conditions is limited more by the method of analysis rather than the measurements (Rossow 1995). Thus, the analysis of high-latitude remote sensing data under cloudy conditions is impeded by an array of interpretation problems related to the lack of appreciable contrast between clouds and the underlying surface in visible, thermal, and microwave channels (e.g., Curry et al. 1996; Jeffries and Dean 1994, and references therein; Raschke et al. 1992; Rossow and Garder 1993). Nevertheless, progress is being made in the analysis methods applicable to polar regions (e.g., Carsey 1993; Dutton et al. 1991; Francis 1994; Han et al. 1999; Hahn et al. 1995; Key and Barry 1989; Key and Haeflinger 1992; Robinson et al. 1992; Rossow and Zhang 1995; Serreze et al. 1992; Yamanouchi and Kawaguchi 1992).

Measurements of snow and sea ice extent, snow depth, and sea ice concentration are possible (see Hall 1988 and Barry et al. 1993 for detailed reviews) with visible, near-infrared, or passive microwave sensors on satellites. For example, assessments of snow extent, derived from the National Oceanic and Atmospheric Administration (NOAA) visible and near-infrared imagery 
under cloud-free conditions, have been available for 25 yr (e.g., Kukla and Kukla 1974; Matson et al. 1986; Robinson et al. 1993). Likewise, passive microwave sensors have proven useful for monitoring snow extent and water equivalent, through cloud cover and darkness (Rango et al. 1979; Kunzi et al. 1982; Foster et al. 1984; Goodison et al. 1986; Chang et al. 1987), although there are problems related to the detection of thin dry snow (producing insufficient signal to differentiate it from the underlying surface), and shallow wet snow (having an emittance similar to bare, wet ground).

Major satellite sensors used for sea ice research (Barry et al. 1993) include visible and thermal-band imagery obtained by the NOAA Advanced Very High Resolution Radiometer (AVHRR) (1.1-1.4 km resolution), Landsat (30-80 $\mathrm{m}$ resolution), and the Defense Meteorological Satellite Program (DMSP) (0.6-2.4-km resolution). DMSP imagery has provided nearly daily coverage (Arctic-wide) since 1974 (Barry et al. 1993). Likewise, passive microwave remote sensors have provided lowresolution (25 to $100 \mathrm{~km}$ ) Arctic-wide coverage of ice concentrations with an accuracy of about 5\%-10\% in fall, winter, and spring, and 10\%-20\% in summer (Barry et al. 1993). The lesser accuracy is caused by summer melt affecting the microwave signal (Onstott et al. 1987; Steffen et al. 1993). Recent analyses of satellite passive microwave imagery indicate a significant decrease in Arctic sea ice extent during the period 1978-87, followed by a more rapid decrease from 1987 to 1994 (Johannessen et al. 1995).

\section{NSA-AAO critical questions}

The planned NSA-AAO site studies address scientific issues that relate, both directly and indirectly, to our ability to answer the following critical questions, as well as most other important questions concerning Arctic climate:

- Will the perennial Arctic ice pack survive the ongoing changes in atmospheric composition?

The magnitude of the predicted surface temperature changes in the Arctic raises a real issue as to whether the perennial Arctic ice pack would remain perennial if the predicted changes were, in fact, realized. Disappearance of the ice pack for even part of the year would have a major secondary impact on the climate of at least the Northern Hemisphere.

- What will be the net effect of the atmospheric changes on the strength of the high-latitude global ocean circulation pumps?

Any significant impact on ice pack formation and extent or on ice transport through the Fram Strait would likely have a significant influence on the global thermohaline circulation, and hence, on global climate.

- Why do current GCMs fail in reproducing observed temperature trends over the Arctic Ocean?
Current GCMs predict that the greenhouse warming will be greatest over the Arctic Ocean and smaller over the Arctic land. Just the reverse has been observed over the last few decades (Chapman and Walsh 1993; Kahl et al. 1993; Walsh 1993). The explanation may be as simple as inadequate GCM vertical resolution near the surface, but that is by no means certain. The inadequacy of the historical database on surface air temperatures over the Arctic Ocean may have contributed to the apparent discrepancy. What is certain is that high-latitude processes, controlling cloud formation/dissipation, seasonal freezing/thawing of the active layer and permafrost, and precipitation-snow cover, are poorly simulated in the present generation of GCMs.

These critical questions can be addressed in terms of the primary and secondary issues discussed below. The primary issues deal with specific high-latitude processes and the need to incorporate those accurately in global climate models, while the secondary issues concern studies of general interest to ARM that can conveniently and efficiently be conducted at the NSA-AAO site.

\section{NSA-AAO primary scientific focus: High- latitude phenomena}

The primary objective of the NSA-AAO site is the elucidation of high-latitude processes in such a way that their physical description can be accurately and costeffectively incorporated into global climate models or GCMs. These models include parameterizations of a variety of physical, chemical, and biological processes occurring in the coupled atmosphere-surface-subsurface system (over land and ocean), that, taken together and working in concert, are designed to simulate the climate system, with all its relevant feedback mechanisms that dominate climate regionally (e.g., at high latitudes) as well as globally.

It is widely recognized that the melting of snow and ice cover results in an abrupt change in surface albedo, and that this change triggers a whole family of feedback mechanisms. It is not so widely recognized that the initiation and rate of melting is most strongly influenced by downwelling longwave radiation, which at high latitudes is itself dominated by the extent and character of cloud cover, and influenced to a lesser extent by the water vapor profile (Curry et al. 1993; Curry 1995; Curry et al. 1995; Zhang et al. 1996, 1997). Hence, clouds play a critical role in nearly all high-latitude feedback mechanisms, as modulators of the timing and rate of change of surface albedo. In addition, at high latitudes, cloud cover tends to be stratified, nearly continuous [with $90 \%$ total cloud cover during summer (Huschke 1969) and 80\% in winter (Curry and Ebert 1992)], and persistent, and hence plays an even larger role in influencing radiative energy transfer than in most other lo- 
cales. Thus, accurate modeling of radiative energy flows in the presence of clouds is critical.

For climate modeling purposes, the correct modeling of cloud formation, evolution, and dissipation so that the appropriate cloud appears at the right place at the right time, is just as important as modeling radiative transport in the presence of prescribed clouds. At high latitudes, however, ice clouds are present much of the year. This fact complicates cloud modeling considerably. Processes controlling cloud formation-evolution are, in general, poorly understood, particularly in relation to the formation and evolution of ice clouds [see Curry et al. (1996) for a review].

Contrary to what might be anticipated, the Arctic atmosphere is polluted, especially in late winter. Although the total magnitude of the Arctic pollutant sources is modest, pollutant removal from the Arctic atmosphere by natural processes, at this time of year, is very slow. This slow removal leads to significant direct perturbation of the radiation budget (Shaw et al. 1993). Aerosol influences cloud condensation, evolution, and evaporation, and hence, cloud optical properties (Twomey et al. 1984).

Surface albedo has a pronounced impact on radiative transfer through the atmosphere under both clear and cloudy sky conditions (Warren and Wiscombe 1980; Wiscombe and Warren 1980; Warren 1982; Wendler 1986; Grenfell and Maykut 1977; Jin et al. 1994), but high surface albedo has a striking impact on the effects of clouds. Since the albedo of snow is typically greater than the albedo of cloud, clouds over snow-covered surfaces may decrease the fraction of shortwave radiation reflected to space (Tsay et al. 1989), which is just the reverse of their effect over lower-albedo surfaces. So when the snow melts, this cloud feedback may change sign. Thus, there is a need to model/parameterize accurately the radiative properties of high latitude surfaces for inclusion in GCMs.

Clouds do not absorb visible wavelengths, but do absorb those in the near-infrared range, and snow and ice have greater spectral reflectance in the visible than in the near-infrared. Thus, clouds as well as snow-ice surfaces absorb selectively in the near-infrared. This implies that the integrated surface albedo under overcast conditions exceeds the clear-sky value (Grenfell and Maykut 1977; Grenfell and Perovich 1984; Choudhury and Chang 1981; Shine and Henderson-Sellers 1985). The importance of the surface is underscored by recent observational findings indicating that interannual variations of snow cover are, to a large extent, responsible for the interannual variability of surface air temperature over northern land areas, especially during spring (Groisman et al. 1994).

Satellite remote sensing plays a crucial role in characterizing the atmosphere and the underlying surface, broadening the understanding of energy flows over large areas, and extending what is learned at ARM sites to the earth as a whole. Satellite remote sensing depends critically upon an accurate understanding of radiative transfer throughout the atmosphere-surface system. Hence, improvement of high-latitude satellite remote sensing is a relevant and important scientific objective of the North Slope of Alaska ARM site. Snow and icecovered surfaces greatly complicate satellite remote sensing data interpretation. In particular, cloud retrieval results are uncertain because the very low temperature and albedo contrasts in the Arctic make cloud identification from space very difficult (Rossow and Garder 1993; Rossow 1995). A new analysis of surface observations of cloudiness indicate an increase in wintertime cloud cover, while a revised satellite cloud detection algorithm, using $3.7 \mu \mathrm{m}$ in addition to visible $(0.6 \mu \mathrm{m})$ and infrared $(11 \mu \mathrm{m})$ radiances (Yamanouchi and Kawaguchi 1992), suggests an increase in summertime cloudiness.

The major scientific objectives for the NSA-AAO site are to provide

- improved treatment of radiative transfer in the coupled atmosphere-snow-ice-surface (land-ocean) system including horizontally inhomogeneous clouds over horizontally inhomogeneous snow-ice-soil-water surfaces;

- improved treatments of the radiative effects of mixed phase and ice phase clouds, aerosols, and cloud-aerosol mixtures;

- improved description of basic cloud microphysical properties and how they are influenced by atmospheric thermodynamics and aerosol characteristics;

- better understanding of the relative importance of surface and advective fluxes of moisture in the formation of clouds and the sensitivity of the boundary layer clouds to large-scale vertical motion;

- better understanding of the interactions among turbulence, radiation, and cloud microphysical processes in the evolution of the cloudy atmospheric boundary layer.

\section{NSA-AAO secondary scientific focus: Other accessible climate-relevant phenomena}

The North Slope of Alaska ARM site offers attractive opportunities to study certain phenomena that are believed to be important to the achievement of ARM goals, but are not specific to high latitudes. These phenomena form a secondary focus for the NSA-AAO.

On average, marine stratus covers $18 \%$ of the earth's surface (DOE 1991). Since it occurs mostly over open water, it greatly increases the albedo of most of the regions of the earth it covers. The importance of this fact was recognized by the ARM Locale Recommendation Team in recommending that an eastern ocean margin (marine stratus) locale be developed as one of five primary CART sites. Now that only three primary CART sites will be established, it would be helpful to the achievement of ARM objectives if the issues as- 
sociated with marine stratus were addressed, to the extent possible, at the NSA-AAO site. Because stratus is common on the North Slope of Alaska throughout the year, the NSA-AAO site is well positioned to address these issues.

Ice-phase clouds are important globally, not just regionally. However, at lower latitudes, ice-phase clouds occur almost exclusively at high altitudes, where they are much less accessible to researchers. The frequency of occurrence of winter Arctic stratus clouds in the NSA-AAO locale makes ice clouds both climatologically important and relatively easy to study.

The ARM locale recommendation team argued that the high-latent and sensible heat fluxes and their resulting effects in the Gulf Stream merited special study. The Gulf Stream was the fifth recommended primary ARM site. While the NSA-AAO locale does not exhibit such high-latent and sensible heat fluxes over the entire region, open water associated with leads and polynyas do exhibit extraordinarily high fluxes locally in winter. Leads consist of linear open water or thin ice features that are typically 10-1000 m wide, but that may exceed $10 \mathrm{~km}$ near coasts. Polynyas consist of large nonlinear areas of open water and thin ice occurring throughout the pack ice. Polynyas may also form along coasts in connection with offshore winds (Barry et al. 1993). Thus, especially in connection with lee polynyas, which occur conveniently close to shore, the NSA-AAO site offers an attractive opportunity for studying these phenomena. Recent studies of fluxes from leads are reported by Alam and Curry (1997).

Sharp transitions offer special challenges to all models, especially spectral models (W. Budd 1994, personal communication). The ARM Locale Recommendation Team had suggested that a secondary ARM site be selected to address these challenges (DOE 1991). Because the NSA-AAO site encompasses the Arctic Coast, it is appropriate for this task as well.

\section{Selected topics relevant to NSA-AAO research needs}

\section{a. The need for spectral radiation measurements covering the 400-600 $\mathrm{cm}^{-1}$ window}

Identification of longwave radiative transfer problems of global significance that can be conveniently investigated at the NSA CART site, is most easily accomplished by examining the basic physics that control the radiative heating (or cooling) rate. In the context of global climate, significant loss of radiative energy to space takes place in the cold and dry upper troposphere. During the Arctic winter, the near-surface temperature and water vapor concentrations are similar to those of the upper troposphere everywhere on Earth. Thus, the NSA CART site offers the opportunity to study processes contributing to cooling of the planet on a global scale. Since "cooling-to-space" dominates the tropo- spheric cooling everywhere, it is most appropriate to inspect the terms in the equation for the cooling to space, written as

$$
C_{\nu}(z)=\pi B_{\nu}(z) \frac{d T_{\nu}\left(z_{t}, z\right)}{d z},
$$

where $B_{\nu}$ is the Planck function at the temperature $T$, at altitude $z$ for the spectral interval from wavenumber $n$ to $\nu+d_{v}$, and $T_{\nu}$ is the flux transmittance. For discussion purposes $T_{\nu}$ may be written as

$$
T_{v}\left(z_{t}, z\right)=e^{-\tau_{\nu}(z)}
$$

where $\tau_{v}(z)$ is the "effective" optical depth of the atmosphere above $z$, defined as

$$
\tau_{\nu}(z)=c \int_{z}^{z_{t}} k_{\nu} \rho_{a} d z^{\prime},
$$

where $k_{v}$ is the monochromatic absorption coefficient, $\rho_{a}$ is the density of the absorber, and $c$ is an optical depth dependent coefficient to account for the appropriate integration over zenith angle. Thus, the most important quantities are the strength of absorption $\left(k_{\nu}\right)$, the absorber amount $\left(\rho_{a}\right)$, the spectral position $(\nu)$, and the temperature $T$. The vertical temperature gradient is also important, particularly for the strong inversions that often occur during the Arctic winter. However, those effects are not discussed herein.

For an isothermal, hydrostatic atmosphere, in which the absorber density decreases exponentially with $z$, the altitude of maximum cooling to space occurs where the optical depth $\tau_{\nu}(z)=1$ or, at the surface, if $\tau_{\nu}(0) \leq 1$. As the temperature decreases, the Planck function at a given $v$ decreases, and the maximum of the Planck function shifts to smaller $\nu$ (Wien's displacement law).

We now examine the distribution of clear-sky radiative heating (Fig. 1), calculated by a detailed line-byline radiative transfer model (Clough et al. 1992) using the McClatchey et al. (1971) sub-Arctic summer and winter atmospheric profiles as input. The difference between sub-Arctic and midlatitude conditions is shown in Fig. 2. Figure 1 shows little cooling in the troposphere below about $3 \mathrm{~km}$, at wavelengths between 0 and 400 $\mathrm{cm}^{-1}$ (strong water vapor absorption), 600-750 $\mathrm{cm}^{-1}$ (strong carbon dioxide absorption), and for $\nu \geq 1500$ $\mathrm{cm}^{-1}$ (strong water vapor absorption and/or small $\mathrm{B}_{\nu}$ ). The maximum spectral cooling is in the middle and upper troposphere and occurs in the pure rotational portion of the spectrum for $\nu<400 \mathrm{~cm}^{-1}$ where as little as $0.1 \mathrm{~cm}$ precipitable water or less makes the atmosphere below about $3 \mathrm{~km}$ completely opaque. The spectral heating from 1000 to $1100 \mathrm{~cm}^{-1}$ in the upper troposphere and lower stratosphere is governed by the distribution of ozone and the temperature profile (this can not be explained in terms of cooling to space). The spectral cooling from 600 to $750 \mathrm{~cm}^{-1}$ in the upper troposphere and lower stratosphere is governed by the spectral properties of carbon dioxide. 

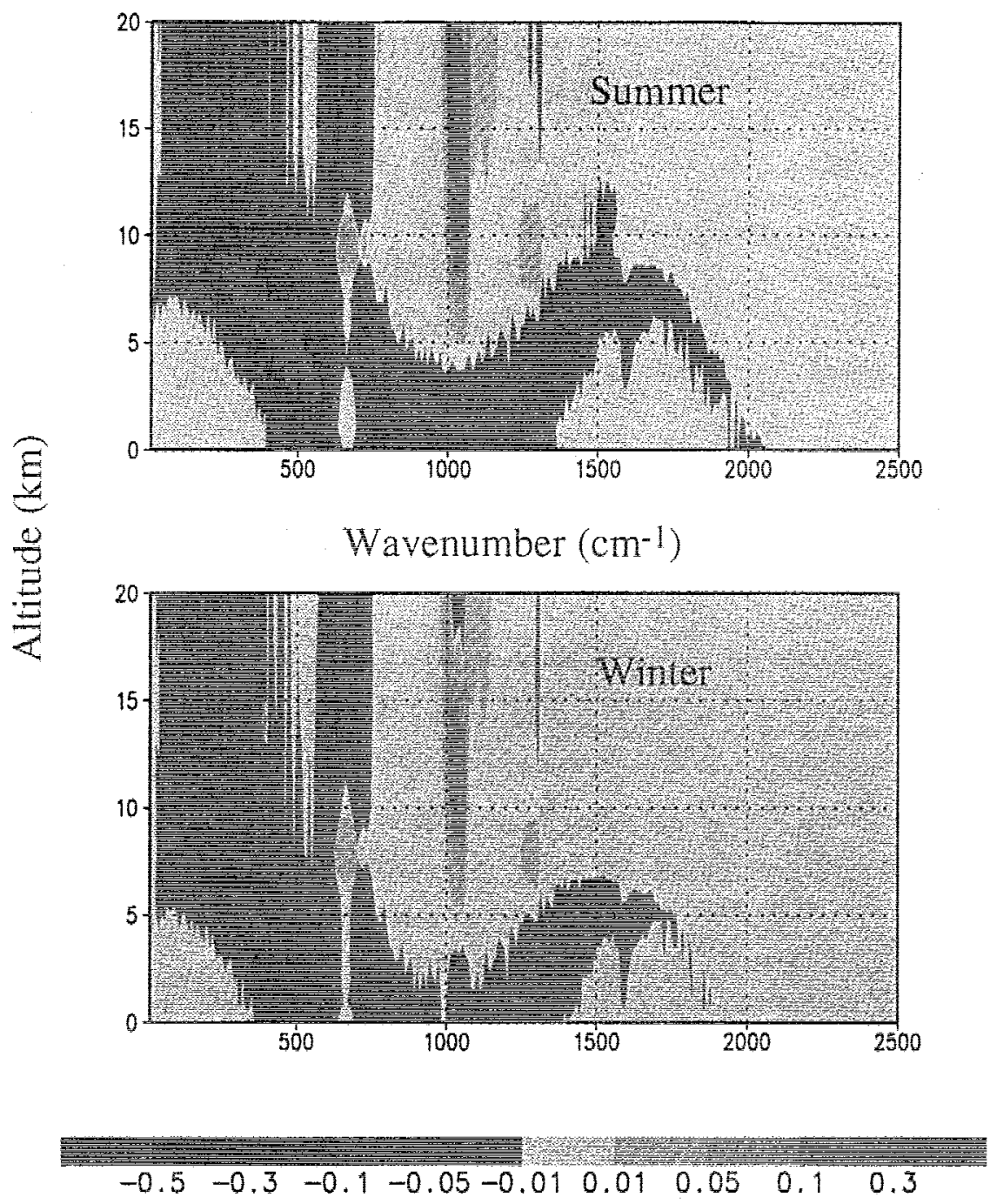

\section{Heating Rate $(0.01 \mathrm{~K} /$ day)}

FIG. 1. Clear-sky spectral radiative heating rate for the sub-Arctic summer and winter model atmospheres.

Since the NSA-AAO CART site will be concerned primarily with observations from the surface, it is important to examine the near-surface cooling in some detail. Summer cooling in the troposphere below about $3 \mathrm{~km}$ is controlled primarily by the atmospheric window region between about 750 and $1250 \mathrm{~cm}^{-1}$ because the optical depths in this region are small and the Planck function is relatively large. The magnitude of the cooling in this portion of the spectrum decreases between summer and winter because of the temperature decrease and the accompanying decrease in the water vapor amount. Note that the sub-Arctic cooling rates in this spectral region are typically lower than those for midlatitudes because of the decreased water vapor amount (summer and winter) and decreased temperature (winter).
The maximum spectral cooling during the summer and winter occurs in the strong pure rotational spectrum of water vapor between about 250 and $600 \mathrm{~cm}^{-1}$. As the water vapor amount decreases between summer and winter, the altitude of maximum cooling for a given wavelength decreases. The comparison to midlatitude winter conditions; shown in Fig. 2 shows this downward shift at all wavelengths in both seasons.

Note, however, that the spectral location of the maximum cooling for the near-surface region has shifted from the $750-1250 \mathrm{~cm}^{-1}$ region to the $400-600 \mathrm{~cm}^{-1}$ region. The altitude shift has occurred because the drier atmosphere has effectively opened this 16-25 $\mu \mathrm{m}$ (400$600 \mathrm{~cm}^{-1}$ ) window to the surface. Furthermore, the maximum of the Planck function has shifted to longer wavelengths as well. 


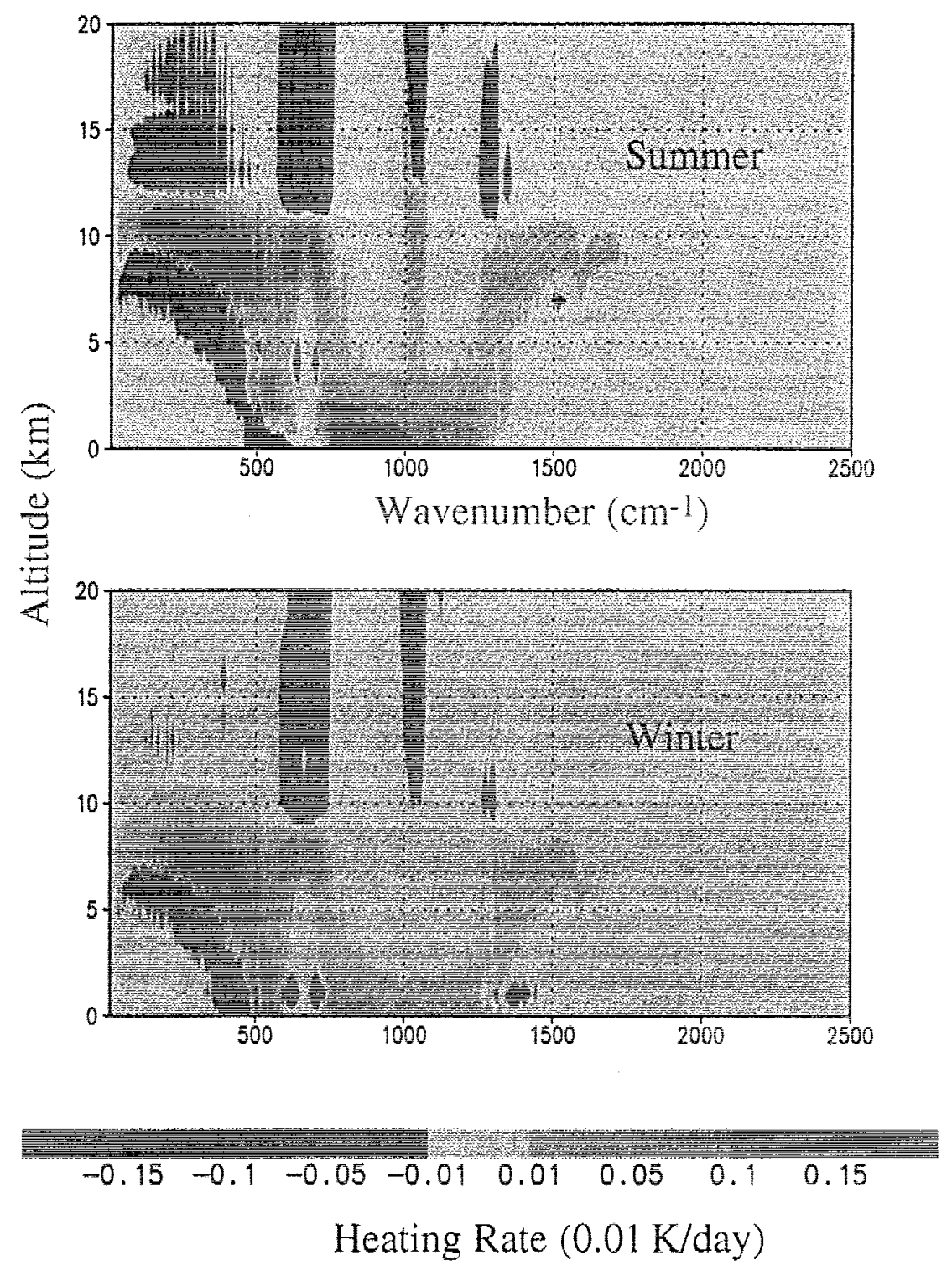

FIG. 2. Difference in clear-sky heating rates between sub-Arctic and midlatitude atmospheres.

The opening of the window and the spectral shift of the Planck function are easily seen in the model spectral distribution of the vertically downwelling radiance at the surface shown in Fig. 3. Regions of low radiance correspond to low-spectral opacity (i.e., one sees partially to space) or to a small Planck function. The smooth, continuous portions of the curve show the envelope of the Planck function for local temperatures. It is easy to visually extrapolate these across the transparent portions of the spectrum and locate the window regions.

Conditions at the planned ARM site at and near Barrow, Alaska, differ frequently from the sub-Arctic atmosphere, as is illustrated in Fig. 4. For the Barrow sounding of 28 February 1986 used in the calculations, the $400-600 \mathrm{~cm}^{-1}$ window has opened substantially, thereby allowing the identification of spectral features to $\nu<400 \mathrm{~cm}^{-1}$. Such conditions are extremely rare for midlatitude sites.

Those interested in the surface energy budget should note that the area between the clear-sky spectrum and the Planck function at the surface temperature for the $400-600 \mathrm{~cm}^{-1}$ interval in Fig. 4 represents about $45 \%$ of the area between the clear-sky spectrum and the Planck function in the $800-1200 \mathrm{~cm}^{-1}$ interval. The addition of a cloud layer will result in near-Planckian radiation from the cloud base reaching the surface through the window regions, assuming clouds are approximately black. Thus, of the increased energy received by the surface as an overcast develops, about $69 \%$ will originate from the $800-1200 \mathrm{~cm}^{-1}$ region, and $31 \%$ will come from the $400-600 \mathrm{~cm}^{-1}$ window. There- 


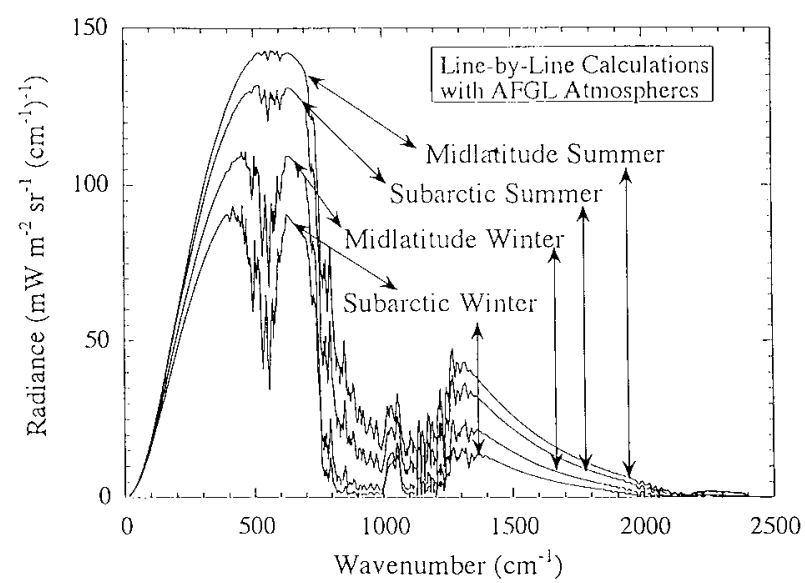

FIG. 3. Downwelling radiance at the surface computed for model atmospheres representing sub-Arctic summer and winter as well as midlatitude summer and winter.

fore, the absorption parameterizations in this region are important for both heating rate and surface energy budget considerations.

Absorption and emission in the $400-600 \mathrm{~cm}^{-1}$ portion of the spectrum is dominated by strong water vapor lines. The parameterization of the absorption of this portion of the spectrum requires not only the specification of the strengths of the local lines, but also the shapes of the lines away from the line centers. Clough et al. (1989) have devoted considerable effort to defining the parameterization of the effects of water vapor line wings, the so-called water vapor continuum, across the entire spectrum, from the laboratory measurements of Burch (1981). The data reported by Clough et al. include temperatures only as low as $296 \mathrm{~K}$ for both the selfand foreign-broadened portions of the continuum. Furthermore, the continuum coefficients in this region are large and are in a region with a substantial spectral gradient. Laboratory measurement errors in this portion of the spectrum translate directly to errors in the magnitude and altitude of the cooling rate.

The observations being taken at the Southern Great Plains CART site with the Atmospheric Emitted Radiance Interferometer (AERI) cover the portion of the spectrum from about 550 to $3000 \mathrm{~cm}^{-1}$. Thus, this device can not see much of the $400-600 \mathrm{~cm}^{-1}$ window region. Furthermore, comparisons of AERI observations with line-by-line calculations for cool, dry conditions at the SGP and for conditions during the Spectral Radiance Experiment (SPECTRE; Ellingson et al. 1993) show the poorest agreement of any spectral region measured by the AERI, in the region from 550 to $600 \mathrm{~cm}^{-1}$. This does not give us great confidence in our ability to calculate fluxes and cooling rates in this portion of the spectrum.

The lower temperatures and water vapor amounts typical of sub-Arctic and Arctic conditions open the 400$600 \mathrm{~cm}^{-1}$ window region of the spectrum to study that

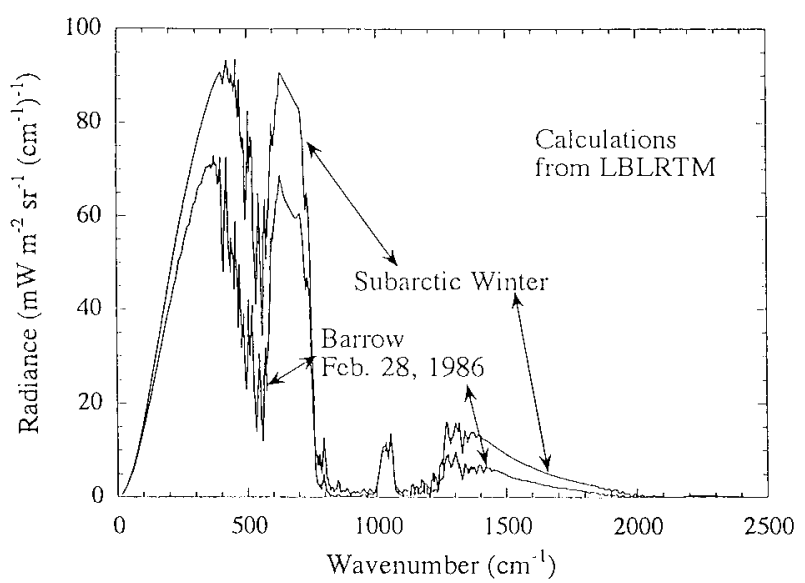

FIG. 4. Comparison between downwelling radiance computed for the sub-Arctic atmosphere and an actual sounding obtained in Barrow, Alaska.

is infrequently available in midlatitudes. This portion of the spectrum contributes strongly to the cooling of the middle troposphere at middle and tropical latitudes, and it is a significant contributor to the near-surface cooling and surface radiation budget of the Arctic. Results from SPECTRE and ARM indicate that models have significant deficiencies in this portion of the spectrum. Furthermore, the current design of the AERI instrument being used at the SGP CART site prohibits this instrument from seeing the entire $400-600 \mathrm{~cm}^{-1}$ window.

In view of the fact that spectrally detailed observations at wavenumbers less than $500 \mathrm{~cm}^{-1}$ are required to validate and improve models of water vapor absorption, it appears that ARM can make a substantial contribution to improving the situation by extending the range of sensitivity of instrumentation planned for the NSA-AAO site to about $350 \mathrm{~cm}^{-1}$. It should be noted, however, that along with such spectral observations must come accurate observations of the vertical profile of water vapor. Such observations appear to be possible only with precision frost-point hygrometers or with Raman lidar.

\section{b. Cloud-radiation feedback over the Arctic Ocean}

The cloud-radiation feedback mechanism may be described for the Arctic Ocean as follows. A perturbation to the Arctic Ocean radiation balance may arise from increased greenhouse gas concentrations and/or increasing amounts of aerosol. A perturbation in the surface radiation balance of the sea ice results in a change in sea ice characteristics (i.e., ice thickness and areal distribution, surface temperature and surface albedo). These changes in sea ice characteristics, particularly the surface temperature and fraction of open water, will modify fluxes of radiation and surface sensible and latent heat, which will modify the atmospheric tempera- 
ture, humidity, and dynamics. Modifications to the atmospheric thermodynamic and dynamic structure will modify cloud properties (e.g., cloud fraction, cloud optical depth), which will in turn modify the radiative fluxes.

The sensitivity of surface and top-of-atmosphere radiation fluxes to variations in Arctic cloud characteristics has been examined by Curry et al. (1993) and Schweiger and Key (1994). The net surface radiation flux increases, in the Arctic, with increased cloud fractional coverage, increased amount of cloud water (liquid and/or ice), or decreased cloud particle size. The effect of clouds on the net surface radiation flux in the Arctic is generally opposite in sign, compared with that of lower latitudes. Curry et al. (1996) estimate that the overall cloud feedback in the Arctic is positive, which is contrary to the estimated negative global cloud feedback. This reversal in sign of the cloud-radiation feedbacks in the Arctic arises from the presence of the highly reflecting snow and/or sea ice, the absence of solar radiation for a large portion of the year, low temperature and water vapor amounts, low cloud water contents, and the presence of temperature inversions. Because of uncertainties in evaluating terms such as the change of cloud fraction with a change in surface temperature, there is uncertainty in the magnitude and even the sign of some components of cloud-radiation feedback. An understanding and correct simulation of the cloud-radiation feedback mechanism require an understanding of changes in cloud fractional coverage and vertical distribution, as the vertical temperature and humidity profiles change; and changes in cloud water content, phase, and particle size, as atmospheric temperature and composition changes.

Several cloud-aerosol feedback processes in the Arctic have been proposed. Curry (1995) has proposed a positive feedback loop between aerosols and clouds in the Arctic. An increased amount of aerosol in the Arctic would increase the amount of cloud water by decreasing the production of precipitation in clouds and thus extending the cloud lifetime. An extended cloud lifetime results in an increase in cloud condensation nuclei production by gas-to-particle conversion processes that occur in the presence of liquid water drops. At the same time, an increase in sulfate aerosol may result in the effective deactivation of ice-forming nuclei, resulting in a decrease in ice water content and an associated decrease in the amount of ice crystal scavenging of the aerosol, and a relative increase in the amount of liquid water content. Thus there is a positive feedback loop between aerosols and clouds, whereby a larger aerosol concentration results in increased cloud water content, which increases the cloud production of aerosols and decreases the cloud scavenging of aerosols, resulting in a net increase in cloud aerosols beyond the original input. Blanchet and Girard (1995) have hypothesized that an increase of sulfuric acid particles would increase the efficiency of ice crystal precipitation, reducing the atmospheric water content, and the net radiation flux at the surface. Since enhanced cooling promotes condensation, a "dehydration feedback" is set up between condensation and the greenhouse effect, leading to an accelerated dehydration and cooling cycle during the Arctic winter. This feedback mechanism can explain in part the observed (Kahl et al. 1993) significant surface cooling and strengthening of the temperature inversion trend over the Arctic Ocean during the cold season.

Cloud-radiation feedback processes are intimately connected with the atmospheric temperature and water vapor feedbacks. A change in surface temperature will give rise to a change in atmospheric temperature and water vapor, including their vertical distribution. The changes in atmospheric temperature and humidity will alter the radiation fluxes and thus the surface temperature. Curry et al. (1995) investigated the water vapor feedback over the Arctic Ocean using 10 yr of radiosonde data obtained from the Russian drifting stations, by taking advantage of the natural variability associated with the annual cycle and the interannual variability. It was found that the water vapor feedback in the Arctic is enhanced by two processes. During the cold half of the year, the dominance of the relative humidity by ice saturation suggests that the relative humidity will actually increase in the lower atmosphere with an increase in temperature, although the length of the period over which ice saturation dominates may be decreased if atmospheric temperatures are uniformly increased over the annual cycle. This results in an enhanced water vapor feedback in the Arctic. Additionally, low moisture content results in significant radiative energy exchange in the water vapor rotation band, which enhances the magnitude of the water vapor feedback in the Arctic.

Because of the impact of clouds on the surface radiation flux and thus the state of the snow-ice surface, and the reciprocal influence of the state of the snowice surface on cloud characteristics, the cloud-radiation feedback processes in the Arctic are inextricably linked with ice albedo feedback processes. Ingram et al. (1989) found that cloud-ice feedbacks were very important, the clouds obscuring surface albedo exchanges and minimizing their effects. On the other hand, Rind et al. (1995) found that inclusion of cloud and water vapor feedback amplified the ice-albedo feedback. In a complex nonlinear system such as the coupled climate system, the total feedback cannot be determined simply by adding the magnitudes of individual feedback processes. Until our physical understanding of the component processes is improved, the interdependence among these feedback processes and their nonlinearities remain uncertain and unquantified.

\section{c. Arctic cloud properties determined from broadband radiometric measurements}

At Barrow, Alaska, completely overcast skies exist frequently throughout the year. The most usual cloud 


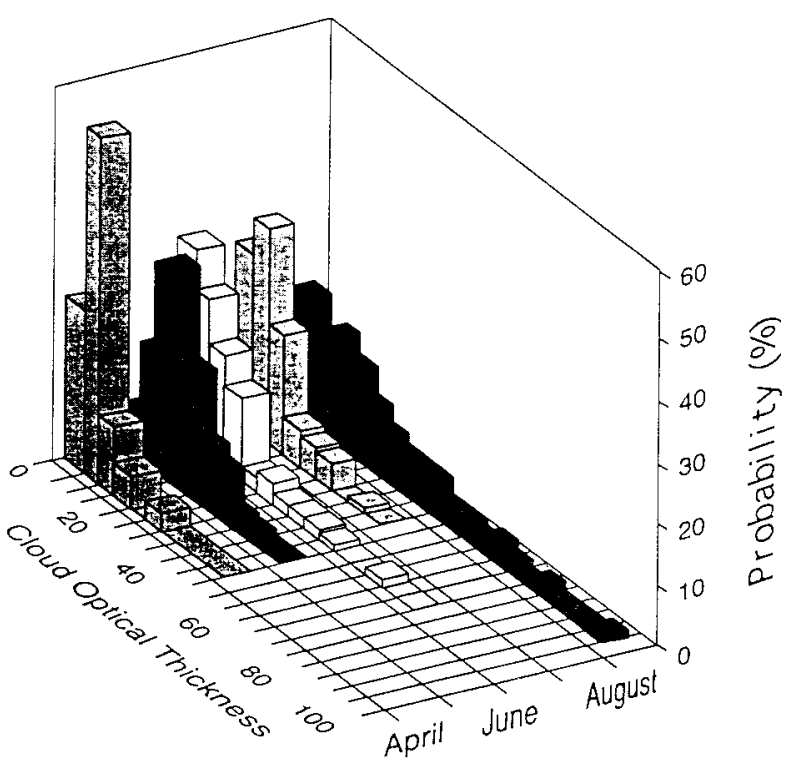

Estimated values of cloud optical thickness at Barrow, Alaska, during Aprit-August 1988

FIG. 5. Estimated values of cloud optical properties at Barrow, Alaska, during April-August, 1988.

types under such conditions (as determined from surface observations precluding observations of upper-layer clouds) are low stratus and fog. The NOAA/CMDL station at Barrow is equipped with Eppley pyranometers that measure downwelling solar irradiance (broadband) as well as shortwave albedo. Similar but more extensive radiometric instrumentation will also be operated at the NSA-AAO CART site. These measurements may be used in conjunction with a radiative transfer model to estimate cloud optical depth, by varying the optical depth in the model until computed downward irradiance agrees with the measured value (Leontieva and Stamnes 1994). For the period from April through August 1988 at Barrow, 68 cases of completely overcast conditions were identified when hourly averaged solar irradiances at the surface (downward and upward), as well as cloud observations and sounding data were available. From these data the seasonal behavior of the cloud optical depth was determined. The results, summarized in Fig. 5 , show that there is considerable seasonal variation in cloud optical depth, with significantly thinner clouds in April than in August.

\section{d. Determination of cloud properties from MFRSR data}

A new instrument deployed in the ARM program is the Multi-Filter Rotating Shadowband Radiometer (MFRSR: Harrison et al. 1994). This instrument provides spectrally resolved diffuse and direct irradiances at six wavelengths: 415, 500, 610, 665, 862, and 940 $\mathrm{nm}$, all with nominal $10-\mathrm{nm}$ bandwidth. A simulation of the atmospheric transmittance of these channels re- veals that the 862-nm channel would be particularly useful for the determination of cloud optical depth (by a procedure similar to that described for the broadband measurements above), because this channel is less affected by atmospheric aerosols than the channels at shorter wavelengths and is free of molecular absorption as well. As in the case of broadband measurements, knowledge of the surface albedo is required for accurate estimation of optical depth (especially for high-surface albedo), but the narrowband channel at $862 \mathrm{~nm}$ is expected to give more accurate optical depth estimates, because unlike the broadband measurements it is not affected by water vapor absorption.

Algorithms have been developed and tested for determining cloud optical depths from the MFRSR data (Leontieva and Stamnes 1996; Min and Harrison 1996). Determination of cloud droplet effective radius is not possible from transmission measurements using only one channel, because a change in droplet size leads to changes in absorption and forward scattering characteristics that tend to compensate for each other so that the transmission is left almost unchanged. Independent determination of cloud optical depth (or liquid water path), from the micrometer radiometer deployed at the CART site, can be used to determine cloud droplet size (Min and Harrison 1996) using only one channel. Alternatively, simulations indicate that cloud droplet equivalent radius could be inferred from bispectral transmittance measurements (using one channel without liquid water absorption, e.g., $862 \mathrm{~nm}$, and one with, e.g., $2.2 \mu \mathrm{m})$. Thus, an additional MFRSR channel at $2.2 \mu \mathrm{m}$ could, in combination with the existing 862-nm channel, yield valuable information on droplet size. This suggests that it would be useful to explore the feasibility of including such a channel in the MFRSR instrument (Leontieva and Stamnes 1996).

\section{e. Radiative transfer in sea ice}

Arctic sea ice plays an important role in the global climate system. The mass balance of sea ice in the Arctic is determined by new ice growth and accretion on multiyear ice floes less the summer melt and ice export, mainly multiyear ice floes through the Fram Strait (Koerner 1973; Barry et al. 1993). The interannual variability in total ice mass is determined mainly by summer melt (Barry et al. 1993), which, in turn, is controlled primarily by the absorption of solar energy; and radiative transfer plays a crucial role in the exchange of energy between atmosphere, sea ice, and ocean. Radiation absorbed within the ice may change its internal structure and thereby modify its optical properties. These changes lead to an alteration of the radiative energy transmitted into the ocean and reflected back to the atmosphere, which, in turn, affects the stratification and circulation of the atmosphere and ocean. To understand these interactions between the atmosphere, sea ice, and ocean, it is necessary to investigate the factors that de- 
termine the disposition of solar radiation within this coupled system, namely the fraction of solar energy absorbed by the ice, transmitted to the ocean, and reflected back to the atmosphere.

To study the radiative transfer process in the coupled atmosphere-sea ice-ocean system, a model has been developed that provides an accurate, self-consistent solution of the radiative transfer equation for the entire system, satisfying appropriate boundary and layer interface conditions, including the reflection and refraction at the air-ice and air-water interface (Jin and Stamnes 1994). The input parameters required by the model are observable physical properties, such as profiles of atmospheric pressure, temperature, gaseous absorbers, cloud (liquid/ice) particle size and concentration, and profiles of ice temperature, density, and salinity. Modeling results indicate that sea ice has a significant impact on the partitioning of solar radiation between the atmosphere, sea ice, and ocean (Jin et al. 1994).

These results show that 1) absorption increases with increasing ice density everywhere in the coupled system, except in the atmosphere, but decreases with increasing salinity, 2) most of the energy absorbed by the sea ice is deposited in the top $10 \mathrm{~cm}$ of the ice, 3) for clear skies over bare ice $50 \%$ of the total solar energy absorbed by the entire system is absorbed by the uppermost $10 \mathrm{~cm}$ of the ice, but clouds and snow on the ice significantly reduce this fraction, 4) beneath $50 \mathrm{~cm}$ in the ice, only visible radiation is left, 5) as the sea ice thickness increases, the absorption increases in the ice, but decreases in the ocean and the entire system, 6) for sea ice thickness greater than about $70 \mathrm{~cm}$ the total absorption (by the entire system) remains constant. Finally, we note that scattering by ice inclusions, especially air bubbles, plays a crucial role in the solar energy partitioning within the entire system. Thus, the air volume fraction in the top layer of the ice seems to be an important parameter.

\section{f. Arctic regional climate system model}

Because radiative transfer affects the distribution of diabatic heating, Arctic cloud-radiative interactions affect the atmospheric circulation and climate regionally (i.e., in the Arctic and sub-Arctic) and quite possibly in areas equatorward from the Arctic. One-dimensional cloud-radiative formulations that are developed and validated with field measurements can be implemented in three-dimensional models in order to assess the regional and global impacts. One such vehicle for regional climate assessments is the Arctic Regional Climate System Model (ARCSYM), which has recently been implemented over an Alaskan domain. The atmospheric component of ARCSYM is a version of the National Center for Atmospheric Research (NCAR) RegCM2 (Regional Climate Model, Version 2). Details of the formulation are given by Giorgi et al. (1993), although recent changes include the implementation of a more efficient semiexplicit time integration technique and, of more relevance to ARM, the radiative transfer scheme of the NCAR Community Climate Model (Version 2: CCM2). ARCSYM also includes a dynamic-thermodynamic sea ice model over the ocean and a land surface soil-vegetation) package known as BATS.1E (Biosphere-Atmosphere Transfer Scheme, Version 1E; Dickinson et al. 1992). Experiments are planned with an alternative land surface package, the Canadian CLASS formulation, designed more specifically for climates in which snow and ice play major roles. As described by Verseghey (1991), the original version of CLASS contains three soil layers with depths of $0.10,0.25$, and $3.75 \mathrm{~m}$ : however, the number of layers is easily expandable to include finer resolution of permafrost and active layer processes.

Recent simulations of the Alaskan domain with ARCSYM (Lynch et al. 1995) span monthly periods during summer and winter. The resolution is $63 \mathrm{~km}$, and the domain includes Alaska, the Bering region, the Gulf and Alaska, and the southern Chukchi-Beaufort Sea. An annual cycle simulation of the Alaskan North Slope at $21-\mathrm{km}$ resolution is now in progress. In all cases, the model is forced laterally by time-varying observational analyses from the European Centre for Medium-Range Weather Forecasts. The early results show warm biases of several degrees Celsius in the simulated surface air temperatures. During the winter, the warm bias appears to be attributable to excessive downward fluxes of longwave radiation, which, in turn, seem to be associated with biases in the simulated cloud properties. However, during the summer, the simulated cloud-radiative interactions appear to bias the model toward anomalously low evaporation rates. It is clear that more accurate representations of the cloud-radiative interactions will be required if the surface temperatures are to be simulated with sufficient accuracy to permit meaningful model experiments with changes in snow cover, permafrost, and trace gas releases. A high priority is the implementation of high-latitude modifications to the model's radiative parameterizations and eventually cloud-radiative formulations developed in conjunction with the ARM NSA-AAO program.

\section{NSA-AAO siting strategy: Phased implementation}

Because of anticipated budget time lines, the NSAAAO CART site needs to be implemented in a phased manner. The phasing described here seeks to take maximum advantage of opportunities for interagency synergism as well as to make optimum use of work already done, or in progress, for earlier CART sites. It is designed so that each phase is a building block for successive phases, but also so that each phase produces results of independent value. 


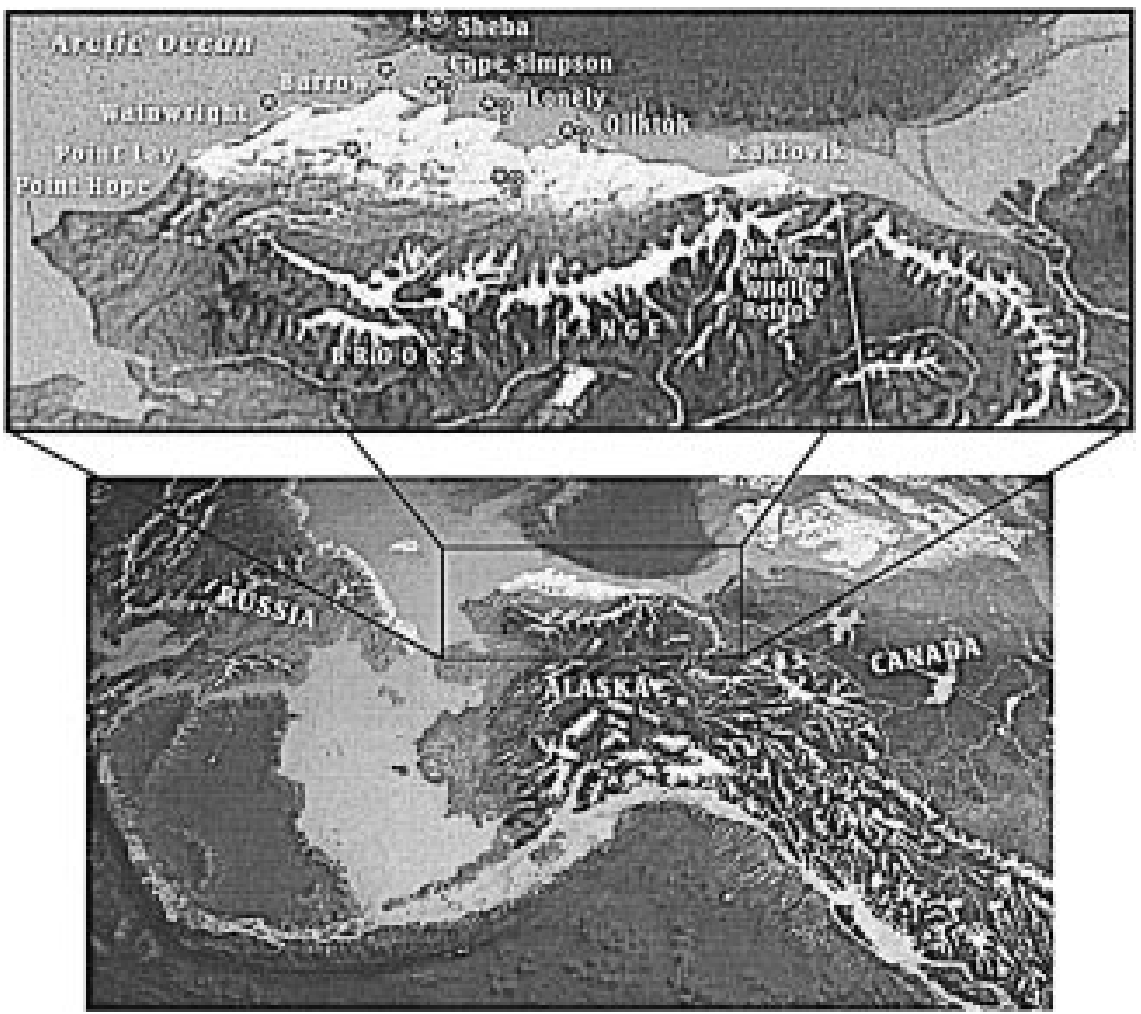

FIG. 6. North Slope of Alaska map. Asterisks mark proposed NSA-AAO instrumentation locations. Asterisks with question marks indicate candidates for the eastern boundary location, one of which is proposed to be chosen.

a. Phase I: Radiative transfer the perennial Arctic ice pack versus coastal environments

Our initial focus is on radiative transfer rather than cloud evolution experiments, because the instrumentation requirements are more modest, and we can begin acquiring one class of needed data at a lesser cost while building toward acquiring the more expensive class of data. We plan to model and accurately measure highlatitude radiative quantities over both land and sea, as well as in the transition region in between. We intend to measure both radiative energy flows and the surface and atmospheric characteristics that influence them, simultaneously within the perennial Arctic ice pack, as part of the SHEBA (Surface Heat Budget of the Arctic Ocean) experiment, and from the ARM facility in the coastal environment of Barrow, Alaska. SHEBA is an interagency effort led by the National Science Foundation and the Office of Naval Research, that is focusing on climate-relevant processes in the perennial Arctic ice pack for a full annual cycle. SHEBA deployment, with ARM participation, took place in October 1997. The ARM facility was formally dedicated on 1 July 1997, and began routine data acquisition early in 1998.

\section{b. Phase II: Radiative transfer, high-latitude coastal versus inland environments}

Once SHEBA ends, the phase II proposal is to move the ARM instrumentation that was part of SHEBA to a site approximately $100 \mathrm{~km}$ inland from Barrow, in the vicinity of the village of Atqasuk (Fig. 6). We anticipate that this inland site will have a significantly more continental character than Barrow (colder and drier in winter, warmer in summer). Taken together, phases I and II will have acquired a transect of radiometric and atmospheric/surface experimental data that should go a long way toward providing the needed understanding of radiative transfer in the Arctic as a whole.

\section{c. Phase III: Cloud formation, evolution, and dissipation}

In phase III, the proposal is to broaden the focus of the NSA-AAO CART site to include high-latitude cloud formation/dissipation experiments. Such experiments must take into account the fact that clouds move. To understand how clouds evolve in time, it is necessary to have multiple instrumentation sets spread over a large area. That will involve the extended CART site: one or two more boundary facilities to the east and/or west of the Barrow-Atqasuk line; augmented automated weather stations over the enclosed area; and perhaps some number of data buoys deployed offshore.

\section{NSA-AAO candidate observations and corresponding instrumentation}

While the instrument complements for the NSAAAO coastal and inland facilities are not yet complete, 
TABLE 1. Observation and instrumentation complement.

\begin{tabular}{|c|c|}
\hline Properties & Instrumentation \\
\hline $\begin{array}{l}\text { Surface radiative fluxes: } \\
\text { broadband } \\
\text { spectral }\end{array}$ & $\begin{array}{l}\text { Solar and IR radiometers } \\
\text { IR thermometer(s) } \\
\text { Rotating shadowband radiometer } \\
\text { Total, diffuse, direct radiometers } \\
\text { sun tracking photometer } \\
\text { Extended spectral range AERI }{ }^{\mathrm{a}}\end{array}$ \\
\hline $\begin{array}{l}\text { Cloud properties: loca- } \\
\text { tion, structure, phase, } \\
\text { sky coverage, optical } \\
\text { depth, emittance }\end{array}$ & $\begin{array}{l}\text { Elastic scatter lidar } \\
\text { Millimeter cloud radar } \\
\text { Whole sky imager } \\
\text { Rotating shadowband radiometer }\end{array}$ \\
\hline $\begin{array}{l}\text { Whole atmosphere: water } \\
\text { vapor, liquid water col- } \\
\text { umn densities; tempera- } \\
\text { ture, humidity, wind } \\
\text { speed and direction } \\
\text { profiles }\end{array}$ & $\begin{array}{l}\text { Microwave radiometer } \\
\text { Microwave temperature profiler } \\
\text { Rawinsonde } \\
\text { Extended spectral range AERI }{ }^{\mathrm{a}} \\
\text { 915- and/or } 449-\mathrm{MHz} \text { wind profiler } \\
\quad \text { with RASS }\end{array}$ \\
\hline $\begin{array}{l}\text { Aerosols: optical depth, } \\
\text { vertical profiles, near- } \\
\text { surface character }\end{array}$ & $\begin{array}{l}\text { Sun tracking photometer } \\
\text { Rotating shadowband radiometer } \\
\text { Elastic scatter lidar } \\
\text { Aerosol collection and sizing } \\
\text { Multiwavelength nephelometer } \\
\text { Aethelometer }\end{array}$ \\
\hline $\begin{array}{l}\text { Boundary layer structure: } \\
\text { temperature, wind, hu- } \\
\text { midity, and turbulence } \\
\text { profiles }\end{array}$ & $\begin{array}{l}\text { 915- and/or } 449-\mathrm{MHz} \text { wind profiler } \\
\quad \text { with RASS } \\
\text { Rawinsonde } \\
\text { Multilevel instrumented tower }\end{array}$ \\
\hline $\begin{array}{l}\text { Surface meteorology: } \\
\text { wind speed and direc- } \\
\text { tion, temperature, pres- } \\
\text { sure, humidity, precip } \\
\text { rate, and integrated pre- } \\
\text { cip }\end{array}$ & Surface met station with tower \\
\hline $\begin{array}{l}\text { Surface characterization: } \\
\text { surface temperature, } \\
\text { moisture, snow depth, } \\
\text { albedo }\left(\mathrm{BRDF}^{\mathrm{b}}\right) \text {, heat } \\
\text { and water vapor fluxes, } \\
\text { snow cover, sea ice } \\
\text { cover }\end{array}$ & $\begin{array}{l}\text { IR thermometer(s) } \\
\text { Thermistor array } \\
\text { Moisture sensors } \\
\text { Snow depth gauge array } \\
\text { Albedo/BRDF' } \text { sensor set }^{\text {Eddy correlation flux system }}\end{array}$ \\
\hline
\end{tabular}

${ }^{a} \mathrm{AERI}=$ Atmospheric Emitted Radiance Interferometer.

${ }^{\mathrm{b}}$ BRDF $=$ Bidirectional Reflectance Distribution Function.

${ }^{\mathrm{c}}$ RASS $=$ Radio Acoustic Sounding System.

the instrumentation suites already at the Southern Great Plains and the Tropical Western Pacific ARM sites have been scrutinized and modified to accommodate the needs at the NSA-AAO site. Table 1 is the current view of the full observation and instrumentation complement. Note that the view put forward here is subject to change.

\section{NSA-AAO status, plans}

In order to begin phase I in concert with SHEBA during fall 1997, preliminary instrumentation deployment to the vicinity of Barrow took place during winter 1996/97. This "cold test" was deemed necessary to avoid deploying instrumentation to SHEBA with which one had no Arctic experience. To meet the schedule, the basic (non-Arctic) instrumentation testing was done dur-

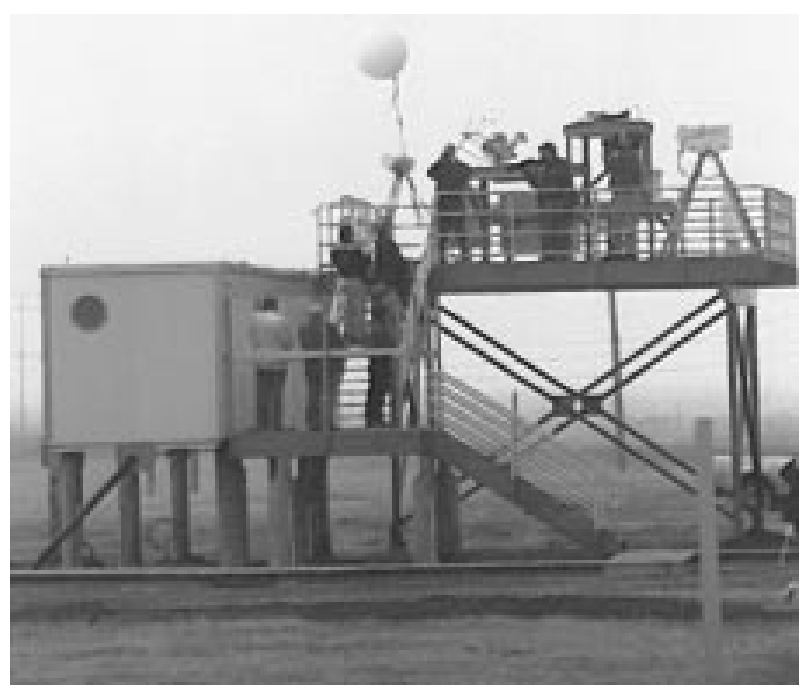

FIG. 7. Photograph of the ARM site in Barrow taken during the site dedication on 2 July 1997.

ing summer and fall of 1996. Overall site planning, environmental assessment, permit-supporting studies, and preliminary engineering were completed by March 1997. Major site construction near Barrow took place during April-May 1997 on NOAA/CMDL land. A 1.2 $\times 2.5 \times 2.5 \mathrm{~m}$ shelter with adjoining decks for outdoor instrument deployment was installed, as well as a $40 \mathrm{~m}$ meteorological tower. A photograph of the site is provided in Fig. 7. The official NSA-AAO site dedication took place on 1 July 1997. Instrument installation and checkout was completed by early 1998 . The Barrow site was operational in time for the ARM-SHEBA-FIRE (First International Satellite Cloud Project Regional Experiment) intensive observation period that started in March 1998.

\section{National/international connections and synergisms}

The extension of the North Slope of Alaska (NSA) ARM effort to the Adjacent Arctic Ocean (AAO) is taking place in conjunction with SHEBA, a 1-yr field experiment based at a manned drifting sea ice camp in the perennial pack ice of the Arctic Ocean. This \$20 $\mathrm{M}+$ experiment is led by the National Science Foundation as part of its Arctic System Science (ARCSS) program, and by the Office of Naval Research. The SHEBA field program was deployed to the Arctic Ocean on a Canadian icebreaker in fall 1997. The SHEBA observational effort will emphasize the relationship between radiative fluxes (especially as affected by surfaceand cloud-radiative interactions), the mass balance of sea ice, and the storage and retrieval of energy and salt in the mixed layer of the ocean. As described by Zak et al. (1997, unpublished manuscript), SHEBA and the ARM NSA efforts have been designed to maximize their synergism. In effect, SHEBA extends ARM/NSA onto the ice-covered waters of the Arctic Ocean. 
Another ARCSS effort that is of direct relevance to ARM/NSA is the Arctic trace gas "Flux Study" of the Land-Atmosphere-Ice-Interactions (LAII) component of ARCSS. The Flux Study consists of 1) measurements of fluxes of trace gases (carbon dioxide, methane) to the atmosphere and of water-transported materials to the ocean, 2) determination of the primary controls of the fluxes, and 3) scaling and synthesis of results to the regional scale (Alaskan North Slope and beyond). The primary field sites are in the Kuparuk drainage basin of the Alaskan North Slope, but measurements are also planned and ongoing near Barrow and Atqasuk, as well as along the line that connects them. The ultimate goal of this study is to assess the feedbacks between climatic change and the release of greenhouse gases from Arctic terrestrial regions. The LAII Flux Study interfaces with the ARM/NSA effort both geographically (through field measurements in adjacent regions of the North Slope) and scientifically (through the link between surface radiative fluxes, soil/vegetation temperature and wetness, and rates of trace gas flux from/to terrestrial ecosystems). The "scaling and synthesis" component of the LAII Flux Study utilizes the Arctic Regional Climate System Model (ARCSYM), which is now being run over a domain that encompasses both the LAII Flux Study area and the proposed ARM/NSA-AAO CART site.

The Arctic Climate System Study (ACSYS) is a new initiative of the World Climate Research Program (WCRP 1992; WCRP 1994). ACSYS is expected to span a period of approximately $10 \mathrm{yr}$. ACSYS emphasizes the climate component of the Arctic system through its focus on the Arctic Ocean, its sea ice cover, and its energy and water budgets. A topic of particular emphasis in ACSYS is the cloud-radiative interaction that is crucial to a quantitative description and understanding of the surface energy budget in the Arctic. Both ARM/NSA-AAO and SHEBA are U.S. contributions to ACSYS. It is expected that the findings of ARM and SHEBA will directly impact the ACSYS-coordinated ice-ocean modeling, which will likely be the key to an assessment of the stability of Arctic sea ice in a changing climate.

Phase III of the First ISCCP (International Satellite Cloud Climatology Project) Regional Experiment (FIRE III; also known as FIRE Arctic Cloud) is a NASA-led effort that will take place in the Arctic in conjunction with SHEBA and NSA-AAO. The emphasis of FIRE is to provide in situ data, which are currently lacking, on cloud radiative properties, to validate and improve satellite retrievals and GCM performance in the Arctic. Instrumented aircraft will play a major role in FIRE. Instrumented aircraft measurements are planned over both the SHEBA and the ARM/NSA-AAO sites. Coordination between the FIRE III, ARM, and SHEBA programs in the Arctic is facilitated by the presence of several members of the FIRE III Science Team on the SHEBA Science Working Group, the ARM Science
Team Executive Committee, and the ARM/NSA-AAO Advisory Panel.

\section{Conclusions}

The climate of the Arctic is linked to and influences the rest of the planet through several mechanisms, including the following:

- Subsidence of brine rejected from sea ice during its formation is a significant pump for the global ocean thermohaline circulation, which affects climate everywhere. Coupled ocean-atmosphere models indicate that changes in the climate of the Arctic are likely to affect the amount of brine formation, and hence, the strength, and possibly the character, of the thermohaline circulation.

- Transport of freshwater via sea ice discharge through the Fram Strait, from the Arctic Basin into the deepwater formation zone of the North Atlantic, affects the global ocean thermohaline circulation.

- Changes in cloud-radiation-sea ice-ocean interactions affect sea ice mass balance and thereby the amount of sea ice available for transport out of the Arctic Basin through the Fram Strait.

- Potential thawing of the permafrost could cause the release of carbon from the tundra, and make the Arctic a net source, rather than a sink, of atmospheric carbon. About one third of the global carbon is presently immobilized in the active layer and permafrost underlying about one fourth of the earth's land surface, mostly in the Arctic.

Complex physical processes involving radiation are essential to understanding climate change in the Arctic. The Arctic plays a role in determining general weather patterns, at least in the Northern Hemisphere, and any shift in those patterns would be broadly felt. The broad influence of the Arctic emphasizes the importance of the following issues to be directly or indirectly addressed at the high-latitude ARM site:

- The cloud-radiation feedback is complicated by the presence of high-albedo snow/ice surfaces, and the lack of sunshine through the long winter. Compared to lower latitudes, the feedback for low clouds is reversed (warming rather than cooling), in the annual mean, in the Arctic.

- The ice-albedo and the cloud-radiation feedbacks are inextricably linked to one another. Studying one in isolation from the other may be quite misleading.

To monitor climate change in this region, satellite retrievals are essential:

- Satellite passive microwave imagery indicates a significant decrease in Arctic sea ice extent during the period 1978-87, followed by a more rapid decrease from 1987 to 1994.

- Proficiency (or lack thereof) in interpreting satellite 
remote sensing data, to quantify the distribution and character of high-latitude clouds, snow, and sea ice, determines our ability to characterize the atmosphere and surface, and link high-latitude and global phenomena. Improvements in the quality of analysis of solar and thermal satellite datasets for the polar regions under cloudy conditions are required for progress in this area.

What is learned at the high-latitude ARM site will affect not just modeling of high-latitude regions, but the modeling of high altitudes everywhere:

- Like the upper troposphere and stratosphere worldwide, the near-surface atmosphere is cold and dry in the Arctic much of the year. The $25-\mu \mathrm{m}$ water vapor rotation band plays an important role in near-surface radiative cooling at high latitudes, as well as in the loss of radiative energy to space globally.

- Spectrally detailed observations at wavenumbers less than $500 \mathrm{~cm}^{-1}$, coupled with accurate observations of the vertical profile of water vapor, such as will be made at the high-latitude ARM site, are required to test and improve the models of water vapor absorption used globally.

- As in the upper troposphere worldwide, ice clouds are frequently present in the Arctic boundary layer. Ice clouds play an important role in near-surface radiative transfer at high latitudes, as well as in the cloud greenhouse effect globally. The high-latitude ARM site is ARM's ice cloud laboratory.

We have discussed the most important scientific issues of Arctic, as well as global, significance to be addressed at the high-latitude ARM site, and provided a brief summary of the current status of site development and deployment. Cold regions are not nearly as well understood as are historically more accessible and hospitable regions. In light of the issues discussed, it is anticipated that in the coming years, use of data from the NSA-AAO CART site will have a profound effect on the quality of radiative and cloud modeling everywhere that the atmosphere is cold, and hence, on the credibility of regional and global climate change predictions.

\section{REFERENCES}

Alam, A., and J. A. Curry, 1997: Determination of surface turbulent fluxes over leads in Arctic sea ice. J. Geophys. Res., 102, 33313344

Barry, R. G., M. C. Serreze, J. A. Maslanik, and R. H. Preller, 1993: The Arctic sea ice-climate system: Observations and modeling. Rev. Geophys., 31, 397-422.

Belmont, A. D., 1957: Lower tropospheric inversions at Ice Island T-3. Polar Atmosphere Symposium, R. Sutcliffe, Ed., Pergamon Press, 215-285.

Blanchet, J.-P., and E. Girard, 1995: Water vapour-temperature feedback in the formation of continental arctic air: Implication for climate. Sci. Total Environ., 160/161, 793-802.

Bradley, R. S., F. T. Keimig, and H. F. Diaz, 1992: Climatology of surface-based inversions in the North American Arctic. J. Geophys. Res., 97, 15 699-15 712.

Broecker, W. S., M. Andrea, W. Wolfli, H. Oescher, G. Bonani, J. Kennett, and D. Peteet, 1988: The chronology of the last glaciation: Implications of the cause of the Younger Dryas event. Paleo-oceanography, 3, 1-19.

Brown, J., F. E. Nelson, and Y. Shur, 1994: Active layer fluctuations: A multi-decade record. Eos, Trans. Amer. Geophys. Union, 75, 86.

Budyko, M. I., 1969: The effect of solar radiation variations on the climate of the Earth. Tellus, 21, 61-69.

Burch, D. E., 1981: Continuum absorption by H20. AFGL-TR-810300, Air Force Cambridge Res. Lab., Bedford, MA, 32 pp.

Cappellaz, J. A., I. Fung, and A. M. Thompson, 1993: The atmospheric $\mathrm{CH}_{4}$ increase since the last glacial maximum. 1: Source estimates. Tellus, 45B, 228-241.

Carsey, F. D., Ed., 1992: Microwave Remote Sensing of Sea Ice. Geophys. Monogr. Ser., No. 68, Amer. Geophys. Union, 462 pp.

Chang, A. T. C., J. L. Foster, and D. K. Hall, 1987: Nimbus-7 SMMR derive global snow cover parameters. Ann. Glaciol., 9, 39-44.

Chapman, W. L., and J. E. Walsh, 1993: Recent variations of sea ice and air temperature in high latitudes. Bull. Amer. Meteor. Soc. 74, 33-47.

Choudhury, B. J., and A. T. C. Chang, 1981: The albedo of snow for partially cloudy skies. Bound-Layer Meteor., 20, 371-389.

Clough, S. A., F. X. Kneizys, and R. W. Davies, 1989: Line shape and the water vapor continuum. Atmos. Res., 23, 229-241.

_, M. J. Iacono, and J.-L. Moncet, 1992: Line-by-line calculations of atmospheric fluxes and cooling rates: Application to water vapor. J. Geopys. Res., 97, 15 761-15 785 .

Curry, J. A., 1995: Interactions among aerosols, clouds, and climate of the Arctic Ocean. Sci. Total Environ., 160/161, 777-791.

- and E. E. Ebert, 1992: Annual cycle of radiative fluxes over the Arctic Ocean: Sensitivity to cloud optical properties. J. Climate, 5, 1267-1280.

— - - and J. L. Schramm, 1993: Impact of clouds on the surface radiation balance of the Arctic Ocean. Meteor. Atmos. Phys., 51, 197-217.

, J. L. Schramm, M. C. Serreze, and E. E. Ebert, 1995: Water vapor feedback over the Arctic Ocean. J. Geophys. Res., 100, 14 223-14 229.

, W. B. Rossow, D. Randall, and J. L. Schramm, 1996: Overview of Arctic cloud and radiation characteristics. J. Climate, 9, 17311764.

Delworth, T., S. Manabe, and R. J. Stouffer, 1993: Interdecadal variations of the thermohaline circulation in a coupled ocean-atmosphere model. J. Climate, 6, 1993-2001.

Dickinson, R. E., G. A. Meehl, and W. M. Washington, 1987: Icealbedo feedback in a CO2-doubling simulation. Climate Change, 10, 241-248.

— A. Henderson-Sellers, and P. J. Kennedy, 1992: BiosphereAtmosphere Transfer Scheme (BATS) version 1E as coupled to the NCAR community climate model. NCAR Tech. Note NCAR/ TN-387+STR, 72 pp.

DOE, 1991: Identification, recommendation, and justification of potential locales for ARM sites. U.S. DOE Rep. 0494T and 0495T, $160 \mathrm{pp}$.

Dutton, E. G., R. S. Stone, D. W. Nelson, and B. G. Mendonca, 1991: Recent interannual variations in solar radiation, cloudiness, and surface temperature at the South Pole. J. Climate, 4, 848-858.

Ellingson, R. G., W. J. Wiscombe, J. DeLuisi, V. Kunde, H. Melfi, D. Murcray, and W. Smith, 1993: The SPECTral Radiation Experiment (SPECTRE): Clear-sky observations and their use in ICRCCM and ITRA. Proc. of the Int. Radiation Symp., Tallinn, Estonia, 451-453.

Foster, J. L., D. K. Hall, A. T. C. Chang, and A. Rango, 1984: An overview of passive microwave remote snow research and results. Rev. Geophys. Space Phys., 22, 195-208.

Francis, J. A., 1994: Improvements to TOVS retrievals over sea ice 
and applications to estimating Arctic energy fluxes. J. Geophys. Res., 99, $10395-10408$.

Giorgi, F., M. R. Marinucci, and G. T. Bates, 1993: Development of a second-generation regional climate model (Reg CM2). Part I: Boundary layer and radiative transfer processes. Mon. Wea. Rev., 121, 2794-2813.

Goodison, B. E., I. Rubinstein, F. W. Thirkettle, and E. J. Langham, 1986: Determination of snow water equivalent on the Canadian Prairies using microwave radiometry. IAHS Publ., 155, 163-173.

Grenfell, T. C., and G. A. Maykut, 1977: The optical properties of ice and snow in the Arctic Basin. J. Glaciol., 18, 445-463.

—, and D. K. Perovich, 1984: Spectral albedos of sea ice and incident solar irradiance in the southern Beaufort Sea. J. Geophys. Res., 89, 3573-3580.

Groisman, P. Y., T. R. Karl, and R. W. Knight, 1994: Observed impact of snow cover on the heat balance and rise of continental spring temperatures. Science, 263, 198-200.

Hahn, C. J., S. G. Warren, and J. London, 1995: The effect of moonlight on observation of cloud cover at night, and application to cloud climatology. J. Climate, 8, 1429-1446.

Hall, D. K., 1988: Assessment of polar climate change using satellite technology. Rev. Geophys., 26, 26-39.

Han, W., K. Stamnes, and D. Lubin, 1999: Remote sensing of surface and cloud properties in the Arctic from AVHRR measurements. J. Appl. Meteor., in press.

Harrison, L., J. Michalsky, and J. Berndt, 1994: The automated multifilter rotating shadow-band radiometer: An instrument for optical depth and radiation measurements. Appl. Optics, 33, 51185125.

Holmgren, B., L. Spears, and C. S. Benson, 1975: Acoustic soundings of the Fairbanks temperature inversions. Climate of the Arctic, G. Weller and S. A Bowling, Eds., Geophysical Institute, University of Alaska, Fairbanks, 293-306.

Huschke, R. E., 1969: Arctic Cloud Statistics from "Air-Calibrated" Surface Weather Observations. The Rand Corporation, 79 pp.

Ingram, W. J., C. A. Wilson, and J. F. B. Mitchell, 1989: Modeling climate change: An assessment of sea ice and surface albedo feedbacks. J. Geophys. Res., 94, 8609-8622.

IPCC, 1992: Climate Change 1992: The Supplementary Report of the IPCC Scientific Assessment. Intergovernmental Panel on Climate Change. WMO/UNEP, Cambridge University Press, 200 pp.

Jeffries, M. O., and K. G. Dean, Eds., 1994: Third Circumpolar Symposium on Remote Sensing of Arctic Environments, Programs and Abstracts. University of Alaska, Fairbanks, 54 pp.

Jin, Z., and K. Stamnes, 1994: Radiative transfer in nonuniformly refracting media such as the atmosphere/ocean system. Appl. Opt., 33, 431-442.

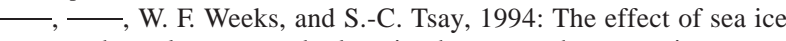
on the solar energy budget in the atmosphere-sea ice-ocean system: A model study. J. Geophys. Res, 99, 25 281-25 294.

Johannesson, O. M., M. Miles, and E. Bjorgo, 1995: The Arctic's shrinking sea ice. Nature, 376, 126-127.

Kahl, J. D., 1990: Characteristics of low-level temperature inversions along the Alaskan Arctic coast. Int. J. Climatol., 10, 537-548.

—, M. C. Serreze, and R. C. Scnell, 1992: Low-level tropospheric temperature inversions in the Canadian Arctic. Atmos.-Ocean, 30, 511-529.

—, D. J. Charlevoix, N. A. Zaitzeva, R. C. Scnell, and M. C. Serreze, 1993: Absence of evidence for greenhouse warming over the Arctic Ocean during the past 40 years. Nature, 361, $335-337$.

Key, J., and R. G. Barry, 1989: Cloud cover analysis with Arctic AVHRR data. 1. Cloud detection. J. Geophys. Res., 94, 85218535.

— , and M. Haeflinger, 1992: Arctic ice surface temperature retrieval from AVHRR thermal channels. J. Geophys. Res., 97, $5885-5893$.

Koerner, R. M., 1973: The mass balance of the sea ice of the Arctic Ocean. J. Glaciol., 12, 173-185.
Kukla, J., and H. J. Kukla, 1974: Increased surface albedo in the northern hemisphere. Science, 183, 709-714.

Kunzi, K. F., S. Patil, and H. Rott, 1982: Snow-cover parameters retrieval from Nimbus-7 scanning multichannel microwave radiometer (SMMR) data. IEEE Trans. Geosci. Remote Sens., GE20, 452-467.

Lachenbruch, A. H., and B. V. Marshall, 1986: Changing climate: Geothermal evidence from permafrost in the Alaskan Arctic. Science, 234, 689-696.

Leontieva, E. N., and K. Stamnes, 1994: Estimations of cloud optical properties from ground-based measurements of incoming solar radiation in the Arctic. J. Climate, 7, 566-578.

— , and —, 1996: Remote sensing of cloud optical properties from ground-based measurements of transmittance: A feasibility study. J. Appl. Meteor., 35, 2011-2022.

Lynch, A. H., W. L. Chapman, J. E. Walsh, and G. Weller, 1995: Development of a regional climate model of the western Arctic. J. Climate, 8, 1555-1570.

Manabe, S., R. J. Stouffer, M. J. Spelman, and K. Bryan, 1991: Transient response of a coupled ocean-atmosphere model to gradual changes of atmospheric $\mathrm{CO}_{2}$. Part I: Annual mean response, J. Climate, 4, 785-818.

Matson, M., C. F. Ropolewski, and M. S. Vanadore, 1986: An Atlas of Satellite-Derived Northern Hemisphere Snow Cover Frequency. Natl. Weather Serv., 75 pp.

Maykut, G. A., and P. E. Church, 1973: Radiation climate of Barrow, Alaska, 1962-66. J. Appl. Meteor., 12, 620-628.

McClatchey, R. A., R. W. Fenn, J. E. A. Selby, F. E. Volz, and J. S. Garing, 1971: Optical Properties of the Atmosphere. Air Force Cambridge Res. Lab., Bedford, MA, 85 pp.

Min, Q., and L. Harrison, 1996: Cloud properties derived from surface MFRSR measurements and comparison with GOES results at the ARM SGP site. Geophys. Lett., 23, 1641-1645.

Nakamura, N., and A. H. Oort, 1988: Atmospheric heat budgets of the polar regions. J. Geophys. Res., 93, 9510-9524.

Oechel, W., S. J. Hastings, G. Vourlitis, M. Jenkins, G. Riechers, and N. Grulke, 1993: Recent changes of Arctic tundra from a net carbon dioxide sink to a source. Nature, 361, 520-523.

Onstott, R. G., T. C. Grenfell, C. Matzler, C. A. Luther, and E. A. Svendsen, 1987: Evolution of microwave sea ice signatures during early summer and midsummer in the marginal ice zone. $J$. Geophys. Res., 92, 6825-6835.

Orvig, S., 1970: Climates of the Polar Regions. Elsevier, 370 pp.

Osterkamp, T. E., T. Zhang, and V. E. Romanovsky, 1994: Evidence of cyclic variation of permafrost in Northern Alaska. Permafrost Periglacial Processes, 5, 137-144.

Rango, A., A. T. C. Chang, and J. L. Foster, 1979: The utilization of spaceborne microwave radiometers for monitoring snowpack properties. Nord. Hydrol., 10, 25-40.

Raschke, E., P. Bauer, and H. J. Lutz, 1992: Remote sensing of clouds and surface radiation budget over polar regions. Int. J. Remote Sens., 13, 13-22.

Rind, D., R. Healy, C. Parkinson, and D. Martinson, 1995: The role of sea ice in $2 \times \mathrm{CO} 2$ climate model sensitivity. Part I: The total influence of sea ice thickness and extent. J. Climate, 8, 449-463.

Robinson, D. A., K. F. Dewey, and R. R. Heim Jr., 1993: Global Snow Cover Monitoring: An update. Bull. Amer. Meteor. Soc., 74, 1689-1696.

, M. C. Serreze, R. G. Barry, G. Scharfen, and G. Kukla, 1992: Large-scale patterns and variability of snowmelt and parameterized surface albedo in the Arctic Basin. J. Climate, 5, 11091119.

Rossow, W. B., 1995: Another look at the seasonal variation of polar cloudiness with satellite and surface observations, Preprints, Fourth Conf. on Polar Meteorology and Oceanography, Dallas, TX, Amer. Meteor. Soc., 1-4.

- , and L. C. Garder, 1993: Validation of ISCCP cloud detections. J. Climate, 6, 2370-2393.

- , and Y.-C. Zhang, 1995: Calculation of surface and top-of- 
atmosphere radiative fluxes from physical quantities based on ISCCP data sets. Part II: Validation and first results. J. Geophys. Res., 100, 1167-1197.

Schweiger, J. A., and J. R. Key, 1994: Arctic Ocean radiative fluxes and cloud forcing estimated from the ISCCP C2 cloud dataset, 1983-90. J. Appl. Meteor., 33, 948-963.

Serreze, M. C., J. D. Kahl, and R. C. Schnell, 1992: Low-level temperature inversions of the Eurasian Arctic and comparisons with Soviet ice island data. J. Climate, 5, 599-613.

—, R. G. Barry, and J. E. Walsh, 1995a: Atmospheric water vapor characteristics at $70^{\circ} \mathrm{N}$. J. Climate, 8, 719-731.

_ M. C. Rehder, R. G. Barry, J. D. Kahl, and N. A. Zaitseva, 1995b: The distribution and transport of atmospheric water vapor over the Arctic basin. Int. J. Climatol., 15, 709-727.

Shaw, G. E., K. Stamnes, and Y.-X. Hu, 1993: Arctic haze: Perturbation to the radiation field. Meteor. Atmos. Phys., 51, 227-235.

Shine, K. P., 1984: Parameterization of the shortwave flux over high albedo surfaces as a function of cloud thickness and surface albedo. Quart. J. Roy. Meteor. Soc., 110, 747-764.

- , and A. Henderson-Sellers, 1985: The sensitivity of a thermodynamic sea ice model to changes in surface albedo parameterization. J. Geophys. Res., 90, 2243-2250.

Spelman, M. J., and S. Manabe, 1984: Influence of oceanic heat transport upon the sensitivity of a model climate. J. Geophys. Res., 89, 571-586.

Steffen, K., J. Key, D. J. Cavalieri, J. Comiso, P. Gloersen, K. St. Germain, and I. Rubinstein, 1993: The estimation of geophysical parameters using passive microwave algorithms. Microwave Remote Sensing of Sea Ice, F. D. Carsey, Ed., Amer. Geophys. Union, 201-231.

Stokes, G. E., and S. E. Schwartz, 1994: The Atmospheric Radiation Measurement (ARM) Program: Programmatic background and design of the cloud and radiation test bed. Bull. Amer. Meteor. Soc., 75, 1201-1221.

Sverdrup, H. U., 1933: The Norwegian North Polar Expedition with the "Maud," 1918-1925, Scientific Results. Geofysisk Institutt, $331 \mathrm{pp}$.

Tao, X., J. E. Walsh, and W. L. Chapman, 1996: An assessment of global climate model simulations of arctic air temperatures. $J$. Climate, 9, 1060-1076.

Tsay, S.-C., K. Stamnes, and K. Jayaweera, 1989: Radiative energy budget in the cloudy and hazy Arctic. J. Atmos. Sci., 46, 10021018.

Twomey, S. A., M. Piepgrass, and T. L. Wolfe, 1984: An assessment of the impact of pollution on global cloud albedo. Tellus, 36B, 356-366.

Verseghey, D. L., 1991: CLASS-A Canadian land surface scheme for GCMs. Part I. Soil model. J. Climatol., 11, 111-133.

Vowinckel, E., and S. Orvig, 1970: The climate of the North Polar Basin. World Survey of Climatology, S. Orvig, Ed., Climates of the Polar Regions, Vol. 14, Elsevier, 129-252.

Walsh, J. E., 1993: The elusive Arctic warming. Nature, 361, 300301.

Warren, S. G., 1982: Optical properties of snow. Rev. Geophys. Space Phys., 20, 67-89.

- and W. J. Wiscombe, 1980: A model for the spectral albedo of snow. II: Effects of aerosols. J. Atmos. Sci., 37, 2734-2750.

WCRP, 1992: Scientific Concept of the Arctic Climate System Study. WMO/TD, 89 pp.

, 1994: Arctic Climate System Study (ACSYS): Initial Implementation Plan. World Climate Research Programme, WMO/TD $66 \mathrm{pp}$.

Weller, G., and Coauthors, 1995: The Arctic flux study: A regional view of trace gas release. J. Biogeogr., 22, 365-374.

Wendler, G., 1986: The "radiation paradox" on the slopes of the Antarctic continent. Polarforschung, 56, 33-41.

Wiscombe, W. J., 1975: Solar radiation calculations for Arctic summer stratus conditions. Climate of the Arctic. G. Weller and S. A Bowling, Eds., Geophysical Institute, University of Alaska, Fairbanks, 245-254.

_ , and S. G. Warren, 1980: A model for the spectral albedo of snow. I: Pure snow. J. Atmos. Sci., 37, 2712-2733.

Yamanouchi, T., and S. Kawaguchi, 1992: Cloud distribution in the Antarctic from AVHRR data and radiation measurements at the surface. Int. J. Remote Sens., 13, 111-127.

Zhang, T., and T. E. Osterkamp, 1993: Changing climate and permafrost temperatures in the Alaskan Arctic. Proceedings of the Sixth International Conference on Permafrost, Vol. 1, S. China University of Technology Press, 783-788.

- K. Stamnes, and S. A. Bowling, 1996: Impact of clouds on surface radiative fluxes and snowmelt at high latitudes. J. Climate, 9, 2110-2123.

- S. A. Bowling, and K. Stamnes, 1997: Impact of the atmosphere on surface radiative fluxes and snowmelt in the Arctic and subArctic. J. Geophys. Res., 102, 4287-4302. 